\title{
Design of CPW-Fed Antenna with Defected Substrate for Wideband Applications
}

\author{
Amar Sharma, ${ }^{1}$ Puneet Khanna, ${ }^{1}$ Kshitij Shinghal, ${ }^{2}$ and Arun Kumar \\ ${ }^{1}$ Electronics and Communication Engineering, IFTM University, Moradabad, India \\ ${ }^{2}$ Electronics and Communication Engineering, MIT, Moradabad, India \\ Correspondence should be addressed to Amar Sharma; amar.charu@gmail.com
}

Received 9 July 2016; Revised 2 November 2016; Accepted 23 November 2016

Academic Editor: John N. Sahalos

Copyright (c) 2016 Amar Sharma et al. This is an open access article distributed under the Creative Commons Attribution License, which permits unrestricted use, distribution, and reproduction in any medium, provided the original work is properly cited.

\begin{abstract}
A CPW-fed defected substrate microstrip antenna is proposed. The proposed antenna shows wideband applications by choosing suitable defected crown shaped substrate. Defected substrate also reduces the size of an antenna. The radiating patch of proposed antenna is taken in the form of extended U-shape. The space around the radiator is utilized by extending the ground plane on both sides of radiator. Simulation of proposed antenna is done on Ansoft's High Frequency Structure Simulator (HFSS v. 14). Measured results are in good agreement with simulated results. The prototype is taken with dimensions $36 \mathrm{~mm} \times 42 \mathrm{~mm} \times 1.6 \mathrm{~mm}$ that achieves good return loss, constant group delay, and good radiation characteristics within the entire operating band from 4.5 to $13.5 \mathrm{GHz}$ $(9.0 \mathrm{GHz})$ with $100 \%$ impedance bandwidth at $9.0 \mathrm{GHz}$ centre frequency. Thus, the proposed antenna is applicable for $\mathrm{C}$ and $\mathrm{X}$ band applications.
\end{abstract}

\section{Introduction}

In the rapid increasing technology of wireless communication, there is a great demand of compact, low profile, low cost, and light weight microstrip antenna [1]. Microstrip antennas are mostly used in military and commercial applications. However, the main disadvantage of microstrip antenna is narrow bandwidth that limits its applications. Enhancement in performance is necessary to cover the demand of wide impedance bandwidth. For obtaining wide impedance bandwidth, lots of techniques have been recommended such as defected structure shape, defected ground structure, slotted patch antenna, stacked patch antenna, and planar monopole antenna [2-7]. Several studies have been reported by the researchers on the microstrip patch antenna with defected ground structure for obtaining wideband/ultrawideband (UWB) $[6,8-11]$. However, in these types of antenna, large space available on both sides of the radiator is not fully utilized and increases the cost of antenna. In these circumstances, coplanar waveguide (CPW) fed microstrip patch antennas play a vital role in utilizing the space available around the radiator [12-18]. In CPW-fed technique the radiating element and the ground plane are on the same side of the substrate. Small amount of work is also reported on defected substrate technique [19]. By making defected substrate, a new structure is formed that shows wideband characteristics.

In this paper, a defected crown shaped substrate wideband microstrip antenna is proposed and designed. The proposed antenna possesses a method to minimize the substrate size so that the overall size of the antenna can be minimized. The proposed antenna uses a crown shaped substrate over the conventional rectangular substrate for reducing the overall dimensions of patch antenna. The ground plane and the radiator plane are on single side of the substrate, so that the large space around the radiator can be fully utilized. In the next section the antenna geometry is discussed in detail. Section 3 covers the parametric study of proposed antenna in detail. Experimental results are discussed in Section 4. Section 5 covers all the discussion made in earlier sections.

\section{Antenna Geometry}

The geometry of the proposed antenna is shown in Figure 1. It has overall dimensions $L_{s} \times W_{s}$ and is fabricated on low cost FR4 substrate of thickness $h=1.6 \mathrm{~mm}$, whose 


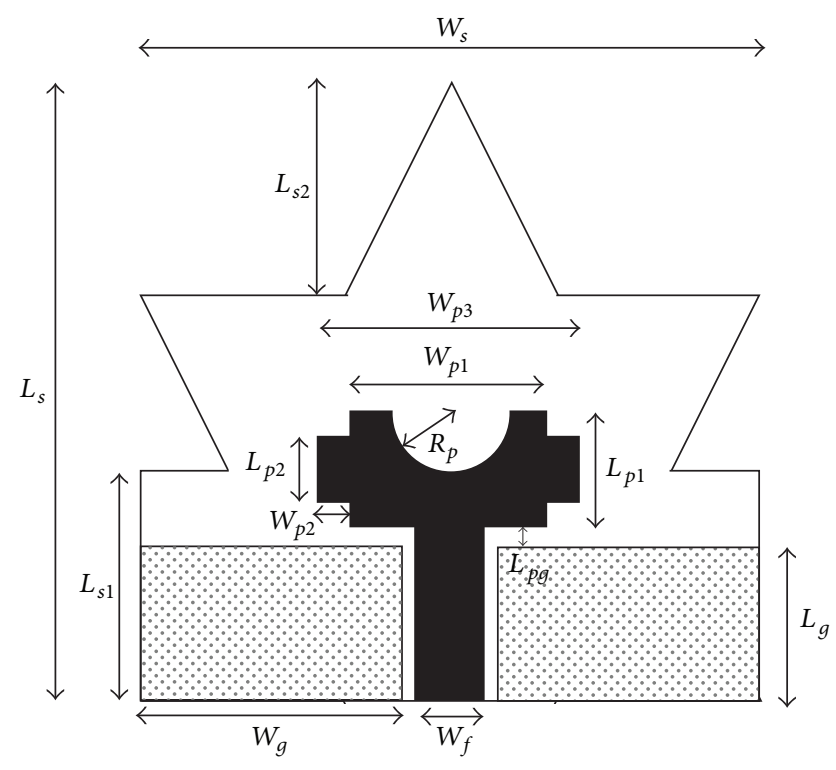

$\uparrow h$

FIGURE 1: Schematic configuration of the proposed defected substrate $\mathrm{CPW}$-fed wideband antenna.

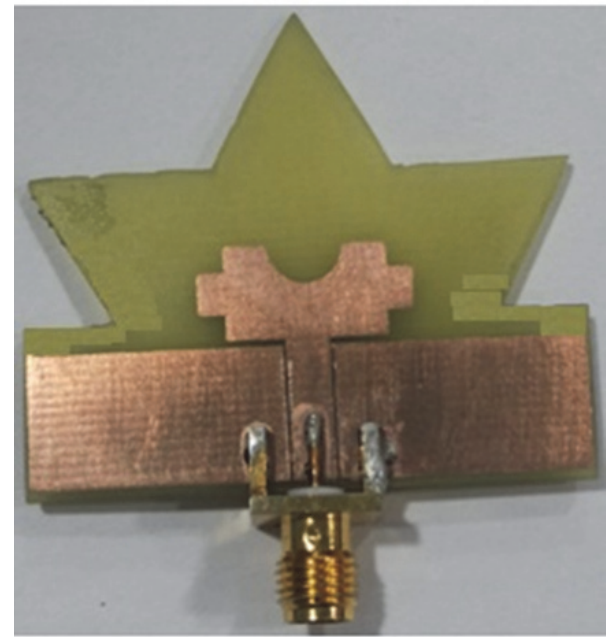

FIGURE 2: Photograph of the fabricated defected substrate CPW-fed wideband antenna.

relative permittivity $\varepsilon_{r}=4.4$ and loss tangent $\tan \delta=$ 0.0019 . A photograph of fabricated defected substrate CPWfed wideband antenna is shown in Figure 2. The size of the proposed antenna is obtained by using mathematical formulation for patch antennas. In the proposed antenna the mathematical modelling is based on rectangular patch, but due to five cutting slots in radiating patch the overall size calculation is not as simple as rectangular patch antenna. Therefore it has been optimized by using electromagnetic solver, Ansoft HFSS simulation software [20]. Designing of radiating patch element includes the estimation of its

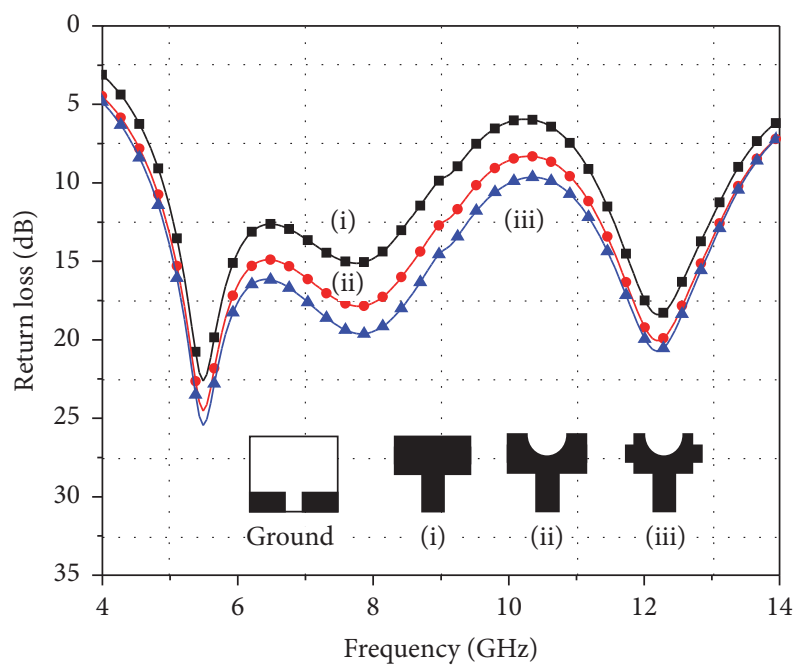

FIGURE 3: Simulated return loss against frequency for the (i) rectangle shape radiator, (ii) arc cut rectangle shape radiator, and (iii) proposed radiator of defected substrate wideband antenna.

dimensions. The patch width $(W)$ has small effect on the resonance and it has been obtained by using the mathematical modelling as shown below [21].

$$
W=\frac{v_{0}}{2 f_{r}} \sqrt{\frac{2}{\epsilon_{r}+1}},
$$

where $v_{0}$ is the speed of light in free space and $\epsilon_{r}$ is the relative permittivity of the substrate material of the proposed antenna. The microstrip patch is on the top of dielectric material; therefore the electromagnetic wave has an effective permittivity $\left(\epsilon_{\text {eff }}\right)$ which is given by [21]

$$
\epsilon_{\mathrm{eff}}=\frac{\epsilon_{r}+1}{2}+\frac{\epsilon_{r}-1}{2}\left[1+\frac{10 h}{W}\right]^{1 / 2} .
$$

The length of the radiating patch $(L)$ plays a major role in finding the resonant frequency and it is an important parameter in designing of patch antenna due to the inherent narrow bandwidth of the patch. The following value of $L$ can be determined by using the following formula:

$$
L=\frac{v_{0}}{2 f_{r} \sqrt{\epsilon_{\text {eff }}}}-2 \Delta l,
$$

where $\epsilon_{\text {eff }}$ is the effective permittivity of the substrate material of the proposed antenna. The additional line length on $\Delta L$ both ends of the patch length, due to the effect of fringing fields, is given by [22]

$$
\frac{\Delta L}{h}=0.412\left[\frac{\epsilon_{\mathrm{eff}}+0.3}{\epsilon_{\mathrm{eff}}-0.258}\right]\left[\frac{W / h+0.264}{W / h+0.813}\right] .
$$

The effective length patch length $L_{e}$ can be written as [21]

$$
L_{e}=l+2 \Delta l .
$$

The further variations in the radiator are shown in Figure 3, having dimensions listed as Table 1 . The base of the microstrip 
TABLE 1: Design parameters of the proposed defected substrate CPW-fed wideband antenna.

\begin{tabular}{lc}
\hline Parameters & Units $(\mathrm{mm})$ \\
\hline$W_{s}$ & 42 \\
$L_{s}$ & 36 \\
$W_{f}$ & 3 \\
$L_{s 1}$ & 12 \\
$L_{s 2}$ & 12 \\
$W_{g}$ & 19.1 \\
$R_{p}$ & 3 \\
$L_{g}$ & 10 \\
$L_{p g}$ & 0.8 \\
$L_{p 1}$ & 7 \\
$L_{p 2}$ & 3 \\
$W_{p 1}$ & 12 \\
$W_{p 2}$ & 2 \\
$W_{p 3}$ & 16 \\
\hline
\end{tabular}

antenna is rectangular in shape which is shown in trace (i) of Figure 3. Initially the shape of the radiating patch antenna is taken as rectangular slot $L_{p 1} \times W_{p 3}$. The simulated result shows that this structure excites at resonating frequencies at $5.48,7.86$, and $12.17 \mathrm{GHz}$ but does not cover the entire operating band from 4.5 to $13.5 \mathrm{GHz}$. After that a semicircular ring is etched in the middle of the radiating patch with radius $R_{p}$ which is shown in trace (ii) of Figure 3; the simulated result shows that this structure improves the return loss condition but still does not cover the entire operating band. Finally, the edges having dimensions $\left(L_{p 1}-L_{p 2}\right) \times W_{p 2}$ are etched on both sides of the radiating patch which is shown in trace (iii) of Figure 3; the simulated result shows that the proposed radiating patch obtains good return loss value but still the return loss is above $10 \mathrm{~dB}$ from 9.96 to $10.68 \mathrm{GHz}$. The detailed dimensions of the proposed defected substrate CPWfed wideband antenna are listed in Table 1.

The ground plane is on the same plane as radiator with two rectangular slits having dimensions $W_{g} \times L_{g}$. The length of gap between the radiating patch and the ground plane is taken as $L_{p g}$. The width of CPW-fed line is fixed at $W_{f}$ to achieve $50 \mathrm{ohm}$ characteristics impedance. The gap between the feed and ground plane is taken as $0.4 \mathrm{~mm}$. The radiator is surrounded by a ground plane with etched substrate that helps to reduce the area. The small gap between the radiator and the ground is a foremost factor to provide strong capacitive coupling.

The simulated surface current distributions on resonant frequencies of $5.48 \mathrm{GHz}, 8.03 \mathrm{GHz}$, and $12.01 \mathrm{GHz}$ are shown in Figure 4. When the microstrip patch antenna is provided with power, a charge distribution appears on the upper and lower part of the patch, as well as on the ground plane. Due to this charge distribution the current will flow at the top and bottom surface of the patch. From this closed analysis of the surface current distribution of the proposed antenna it is found out that at $5.48 \mathrm{GHz}, 8.03 \mathrm{GHz}$, and $12.01 \mathrm{GHz}$ resonant frequency the proposed antenna resonates in TM11 mode, TM21 mode, TM12 mode, respectively. The above mentioned mode can be explained on the basis of surface current distribution of the proposed antenna; from Figure 4(a) it can be observed that the direction of surface current is aligned by the side of circumference and terminated at one point on the circumference of patch; that is, at this location of patch negative node are located and on the opposite side of the patch positive node are located. Thus only one positive node and one negative node are located, which is the case of TM11 mode $[23,24]$. Similarly, from Figure 4(b) it can be observed that the current is aligned and terminated at two points on the circumference of patch. Thus there are two positive and two negative nodes are located, which is the case of TM21 mode. While in Figure 4(c) it can be observed that the current is aligned towards tangential of circumference at two points, which is the case of TM12 mode.

The substrate is etched in the form of crown shape. The variation in substrate is shown in Figure 5, having radiator and ground plane dimensions as listed in Table 1. Initially, a rectangular substrate is taken as shown in trace (i). The simulated result shows that this structure excites at resonating frequencies at $5.48,7.86$, and $12.17 \mathrm{GHz}$ but does not cover the entire operating band from 4.5 to $13.5 \mathrm{GHz}$ as the return loss is above $10 \mathrm{~dB}$ from 9.96 to $10.68 \mathrm{GHz}$. However, when the substrate is taken in the form of triangle shape (trace (ii)), the simulated result shows better return loss but does not cover the entire operating band as return loss is above $10 \mathrm{~dB}$ from 10.13 to $10.46 \mathrm{GHz}$. At last, when the substrate is defected into crown shape, as shown in trace (iii), the simulated result covers entire operating bandwidth $(4.5$ to $13.5 \mathrm{GHz})$ with three resonating bands at $5.48,8.03$, and $12.01 \mathrm{GHz}$. Therefore, it is decided to take defected substrate (crown shaped) antenna for further investigations as it is smaller in size and improves the impedance matching conditions for the entire band.

\section{Parametric Study of the Proposed Antenna}

In this section, the influence of the different design parameters on proposed antenna performance is presented and discussed. At a time, variation in single parameter is done while others are kept constant. The optimization of parameters is helpful for the fabrication of the proposed defected substrate antenna. The effect of change in radiating patch length $\left(L_{p 1}, L_{p 2}\right)$, width $\left(W_{p 1}, W_{p 2}\right)$, inner circle radius $\left(R_{p}\right)$, microstrip feed line $\left(W_{f}\right)$, and length between radiating patch and ground plane $\left(L_{p g}\right)$ is considered for parametric study.

Figure 6 , shows the variation in length of radiating patch $\left(L_{p 1}\right)$ of the proposed antenna from 6 to $8 \mathrm{~mm}$. When $L_{p 1}=6 \mathrm{~mm}$, the return loss remains lower than $10 \mathrm{~dB}$ but bandwidth is reduced ( 4.8 to $13.28 \mathrm{GHz}$ ). With further increase in $L_{p 1}=7 \mathrm{~mm}$, the return loss remains lower than $10 \mathrm{~dB}$ with improved impedance bandwidth from 4.5 to $13.5 \mathrm{GHz}(9.0 \mathrm{GHz})$. However, as $L_{p 1}$ increases to $8 \mathrm{~mm}$, the bandwidth for the return loss does not remain lower than $10 \mathrm{~dB}$ for the entire band. Therefore, it is decided to take $L_{p 1}=7 \mathrm{~mm}$ as the optimum value from 4.5 to $13.5 \mathrm{GHz}$, covering the entire wideband.

The simulated results of the proposed antenna for patch length $L_{p 2}$, from 1 to $4 \mathrm{~mm}$ are depicted in Figure 7 . When $L_{p 2}=1 \mathrm{~mm}$, the bandwidth for the return loss does not 


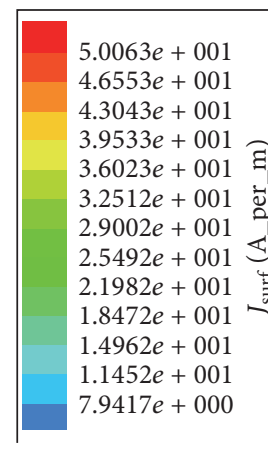

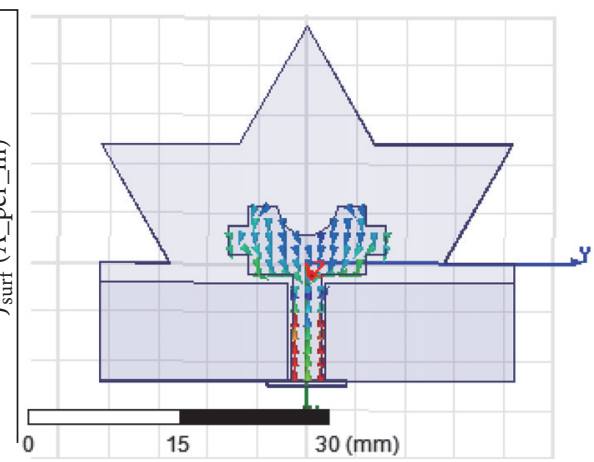

(a)

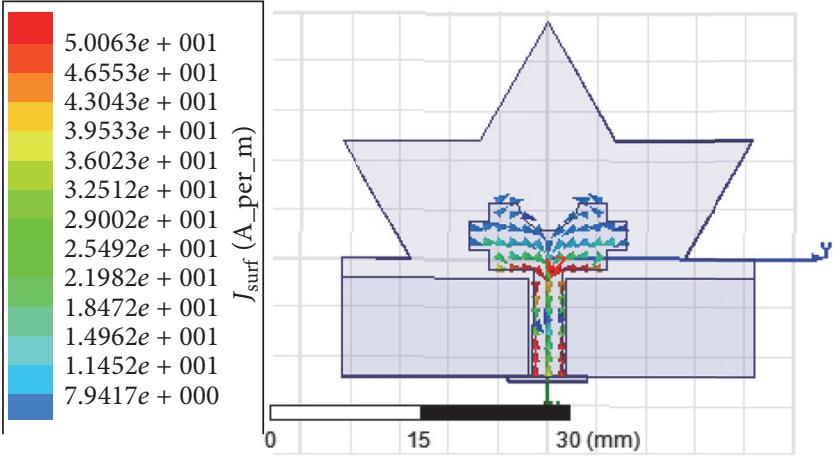

(b)

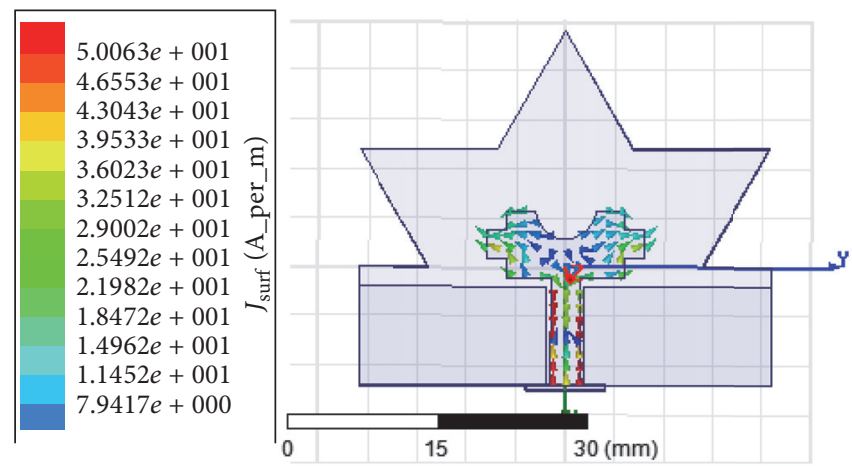

(c)

Figure 4: The surface current distribution on the proposed defected substrate wideband antenna at (a) $5.48 \mathrm{GHz}$, (b) $8.03 \mathrm{GHz}$, and (c) $12.01 \mathrm{GHz}$.

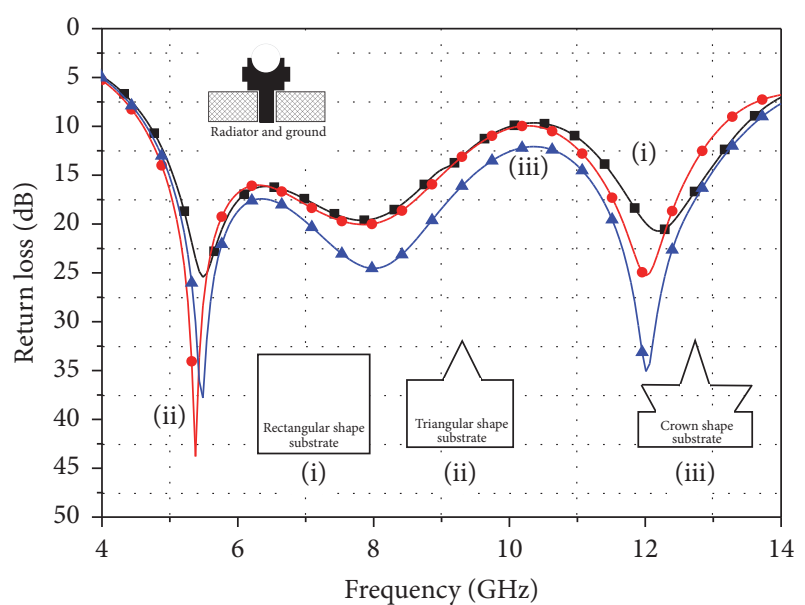

FIGURE 5: Simulated return loss against frequency for the proposed defected substrate (crown shaped) CPW-fed wideband antenna, defected substrate (triangle shape) CPW-fed antenna, and rectangular substrate $\mathrm{CPW}$-fed antenna.

remain lower than $10 \mathrm{~dB}$ for the entire band as it is above $10 \mathrm{~dB}$ between frequencies 9.41 and $10.90 \mathrm{GHz}$. When $L_{p 2}=$ $2 \mathrm{~mm}$ the return loss does not remain lower than $10 \mathrm{~dB}$ for frequencies between 10.24 and $10.60 \mathrm{GHz}$. For $L_{p 2}=$ $3 \mathrm{~mm}$, the bandwidth improves significantly covering the entire band with improved impedance matching. On further

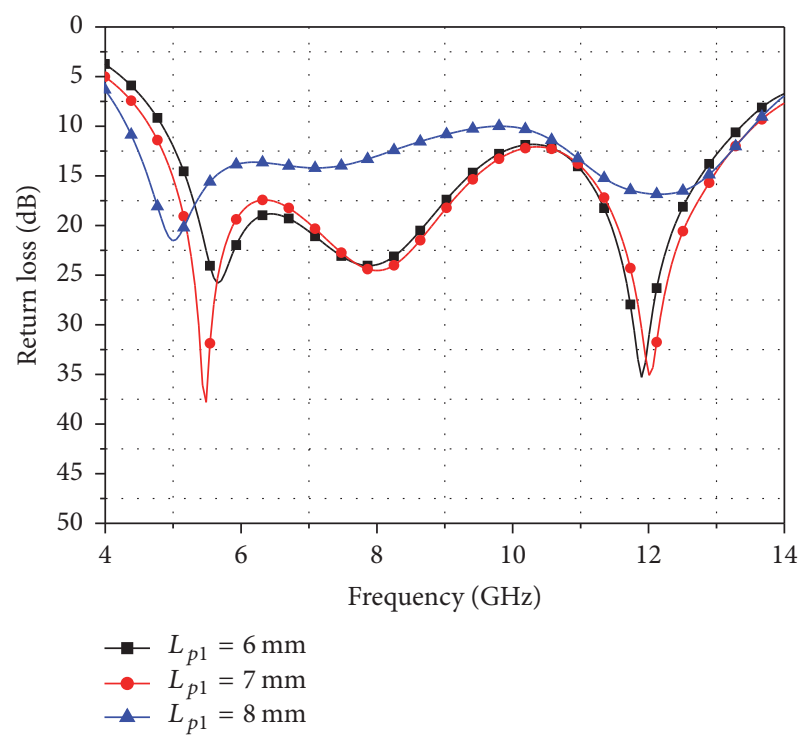

FIGURE 6: Simulated return loss against frequency for the proposed defected substrate wideband antenna with various $L_{p 1}$; other parameters are the same as listed in Table 1.

increase in $L_{p 2}=4 \mathrm{~mm}$, the operational bandwidth decreases and a worse matching condition appears over the frequency band. Therefore, it is decided to take $L_{p 1}=3 \mathrm{~mm}$ as the optimum value covering the band from 4.5 to $13.5 \mathrm{GHz}$, covering the entire wideband. 


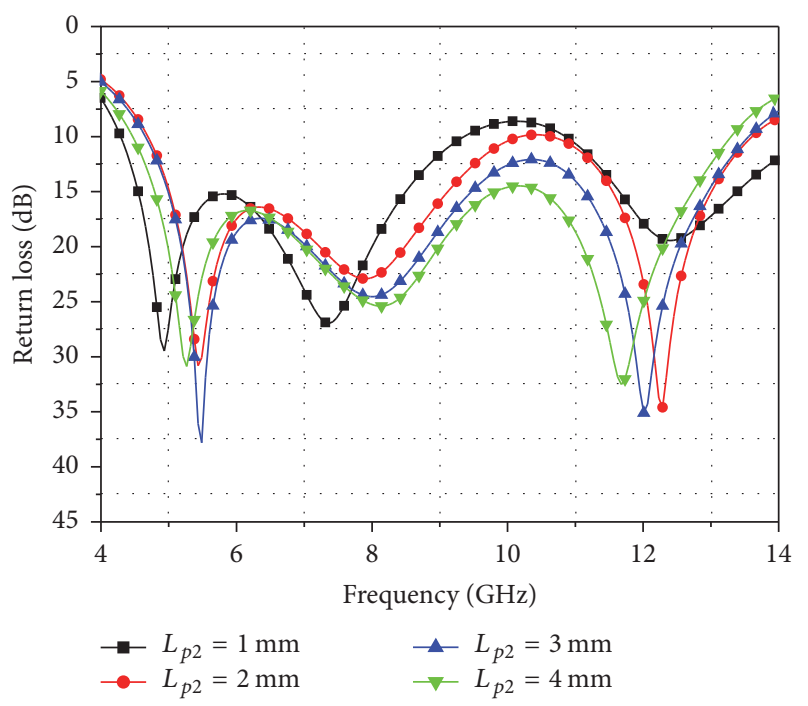

FIGURE 7: Simulated return loss against frequency for the proposed defected substrate wideband antenna with various $L_{p 2}$; other parameters are the same as listed in Table 1.

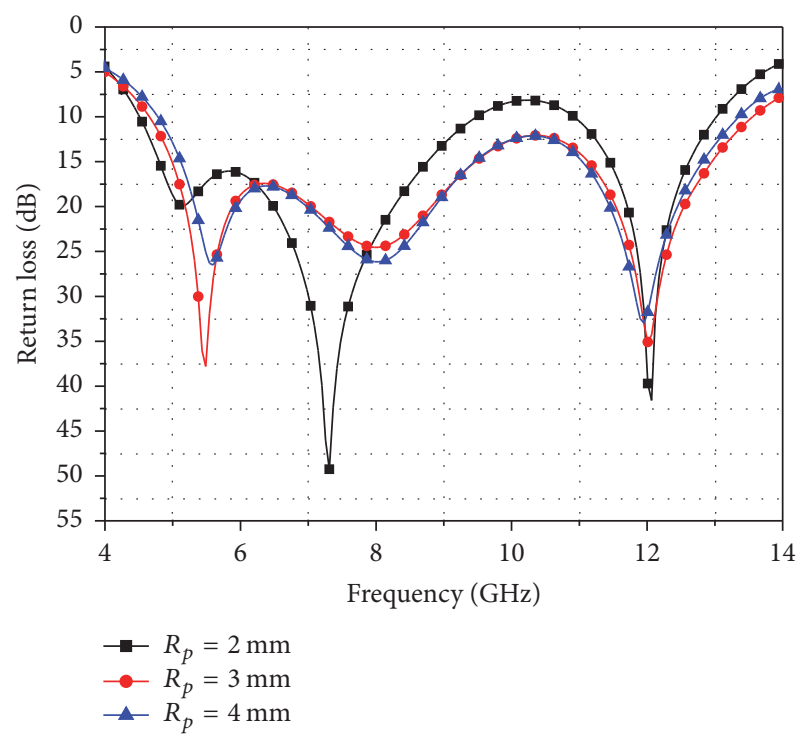

FIGURE 8: Simulated return loss against frequency for the proposed defected substrate wideband antenna with various $R_{p}$; other parameters are the same as listed in Table 1.

Figure 8 shows variation of radius of inner circle of radiating patch $\left(R_{p}\right)$ of the proposed antenna from 2 to $4 \mathrm{~mm}$. As $R_{p}=2 \mathrm{~mm}$, it is observed that the bandwidth of antenna is above $10 \mathrm{~dB}$ from 9.52 to $11.01 \mathrm{GHz}$ and does not cover the entire operating band. However, as the value of $R_{p}$ increases to $3 \mathrm{~mm}$, the impedance matching of the radiating patch and the input impedance improve and cover the entire bandwidth. On further increase of $R_{p}=4 \mathrm{~mm}$, the impedance matching and input impedance of radiating patch deteriorate. Therefore, it is decided to take $R_{p}=3 \mathrm{~mm}$ as the optimum value with the bandwidth from 4.5 to $13.5 \mathrm{GHz}$.

The simulated results of the proposed antenna, with microstrip feed $\left(W_{f}\right)$, varying from 2.9 to $3.1 \mathrm{~mm}$ are illustrated in Figure 9. It can be seen that the bandwidth of return

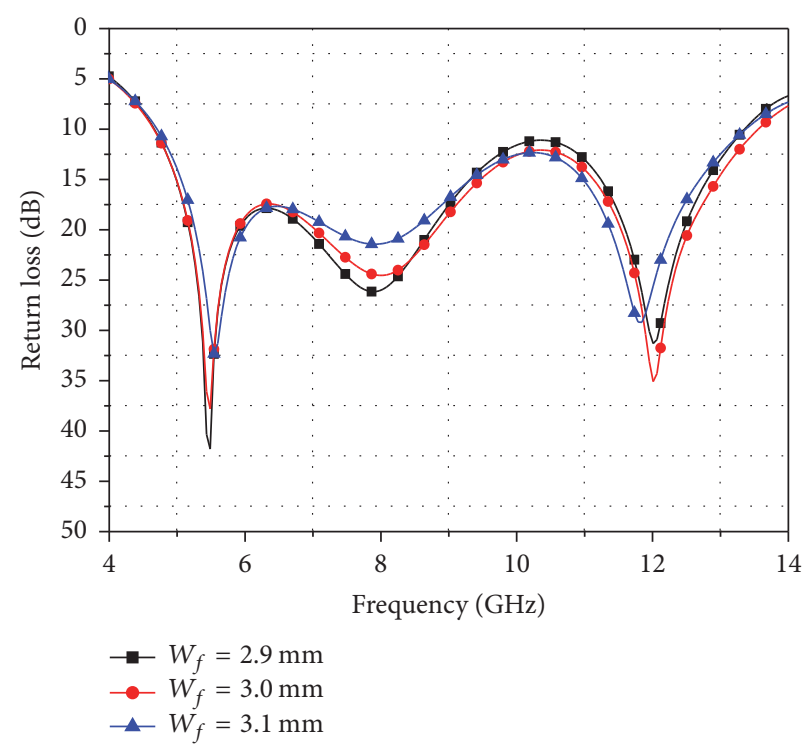

FIGURE 9: Simulated return loss against frequency for the proposed defected substrate wideband antenna with various $W_{f}$; other parameters are the same as listed in Table 1.

loss less than $10 \mathrm{~dB}$ of the antenna remains constant as $W_{f}$ increases from 2.9 to $3.1 \mathrm{~mm}$. However, as $W_{f}$ increases from 2.9 to $3.0 \mathrm{~mm}$, the impedance matching of the radiating patch and the input impedance of the frequency band from 11.20 to $12.32 \mathrm{GHz}$ are improved significantly. With further enhancement in microstrip feed $\left(W_{f}\right)$, it deteriorates. Therefore, it is decided to take $W_{f}=3.0 \mathrm{~mm}$ as the optimum value, with minimum mismatch at higher frequency range.

The variation in patch width $\left(W_{p 1}\right)$ from 10 to $13 \mathrm{~mm}$ is shown in Figure 10. For $W_{p 1}=10 \mathrm{~mm}$ the bandwidth is above $10 \mathrm{~dB}$ for frequencies from 10.68 to $11.40 \mathrm{GHz}$ and does not cover the entire operating band. For $W_{p 1}=11 \mathrm{~mm}$, the bandwidth of return loss remains less than $10 \mathrm{~dB}$, but the total band is reduced from 4.5 to $11.40 \mathrm{GHz}(6.9 \mathrm{GHz})$. However, as width $W_{p 1}$ increases to $12 \mathrm{~mm}$, the impedance bandwidth significantly improves covering the entire band from 4.5 to $13.5 \mathrm{GHz}$. With further increase in $W_{p 1}=13 \mathrm{~mm}$, the bandwidth of return loss is higher than $10 \mathrm{~dB}$ from frequency 10.02 to $10.68 \mathrm{GHz}$. Therefore, it is decided to take $W_{p 1}=$ $12 \mathrm{~mm}$ as the optimum value for the bandwidth from 4.5 to 13.5 GHz, covering the entire bandwidth.

Figure 11, shows the variation of radiator patch width $\left(W_{p 2}\right)$ from 1.0 to $3.0 \mathrm{~mm}$. As $W_{p 2}=1.0 \mathrm{~mm}$, the bandwidth of return loss remains less than $10 \mathrm{~dB}$ for the entire band from 4.6 to $13.8 \mathrm{GHz}$, but the impedance matching of the radiating patch with input impedance deteriorates at higher frequencies. When $W_{p 2}=1.5 \mathrm{~mm}$, the return loss does not remain less than $10 \mathrm{~dB}$ for the entire band as it is above than $10 \mathrm{~dB}$ from frequencies 9.7 to $10.8 \mathrm{GHz}$. As $W_{p 2}=$ $2.0 \mathrm{~mm}$, the impedance matching of the radiating patch and the input impedance at the frequency improve covering the entire bandwidth from 4.5 to $13.5 \mathrm{GHz}$. With further increase in $W_{p 2}$ the bandwidth shrinks and remains between 4.3 and $12.26 \mathrm{GHz}$ for $W_{p 2}=2.5 \mathrm{~mm}$; for $W_{p 2}=3.0 \mathrm{~mm}$ the bandwidth remains 4.7 to $12.45 \mathrm{GHz}$ and does not cover the 


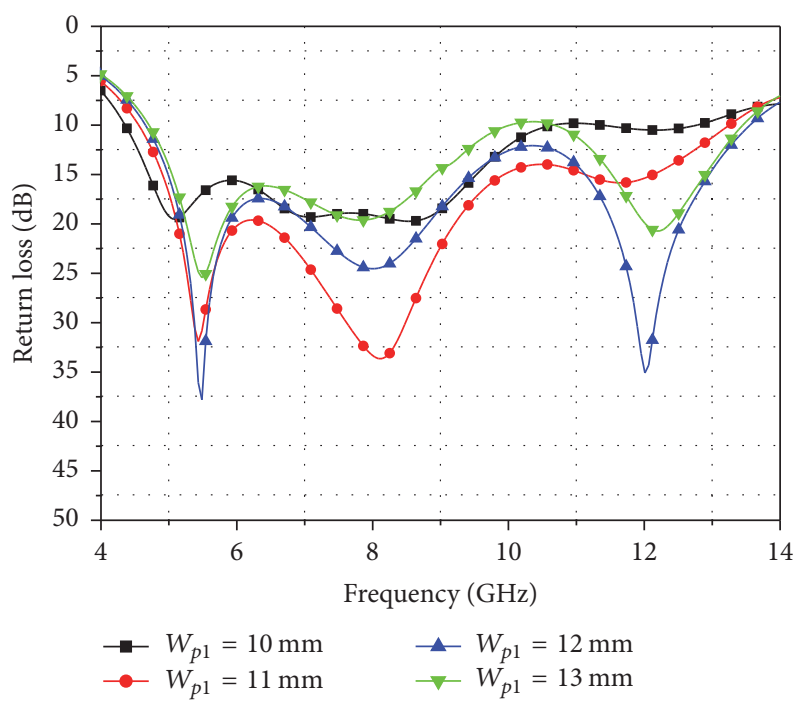

FIGURE 10: Simulated return loss against frequency for the proposed defected substrate wideband antenna with various $W_{p 1}$; other parameters are the same as listed in Table 1.

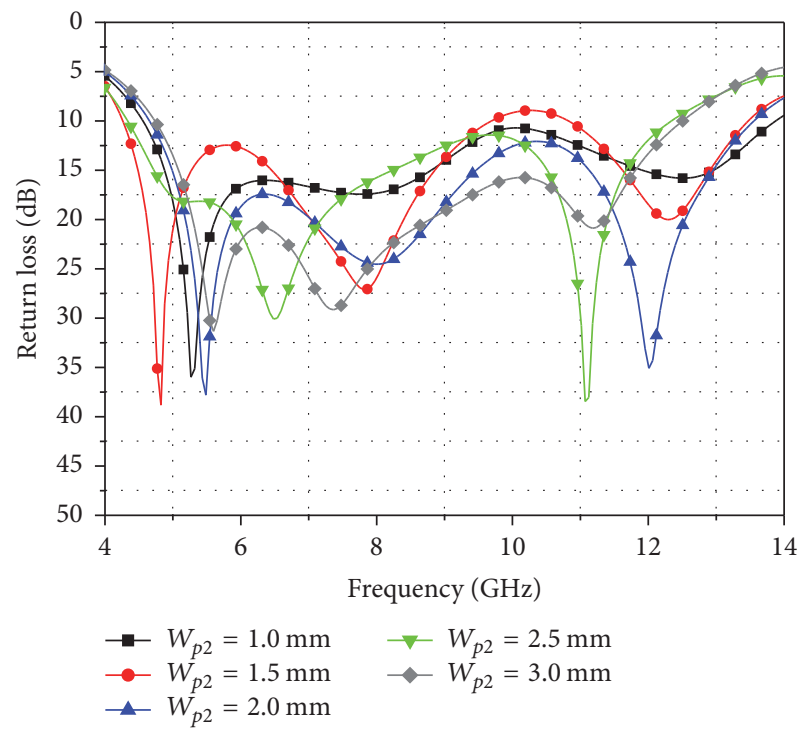

FIGURE 11: Simulated return loss against frequency for the proposed defected substrate wideband antenna with various $W_{p 2}$; other parameters are the same as listed in Table 1.

entire operating band. Therefore, it is decided to take $W_{p 2}=$ $2.0 \mathrm{~mm}$ as the optimum value covering the entire bandwidth from 4.5 to $13.5 \mathrm{GHz}$.

The variation in patch width $\left(L_{p g}\right)$ from 0.6 to $1.0 \mathrm{~mm}$ is shown in Figure 12. When $L_{p g}=0.6 \mathrm{~mm}$, the return loss is less than $10 \mathrm{~dB}$ but the bandwidth is 4.7 to $13.0 \mathrm{GHz}$ which is less than the desired bandwidth. When $L_{p g}=0.8 \mathrm{~mm}$ the bandwidth of return loss remains less than $10 \mathrm{~dB}$ with good impedance matching between radiating patch and input impedance. On further increase of $L_{p g}$ the bandwidth of the return loss is not less than $10 \mathrm{~dB}$ and does not cover the entire bandwidth. Therefore, it is decided to take $L_{p g}=0.8 \mathrm{~mm}$ as

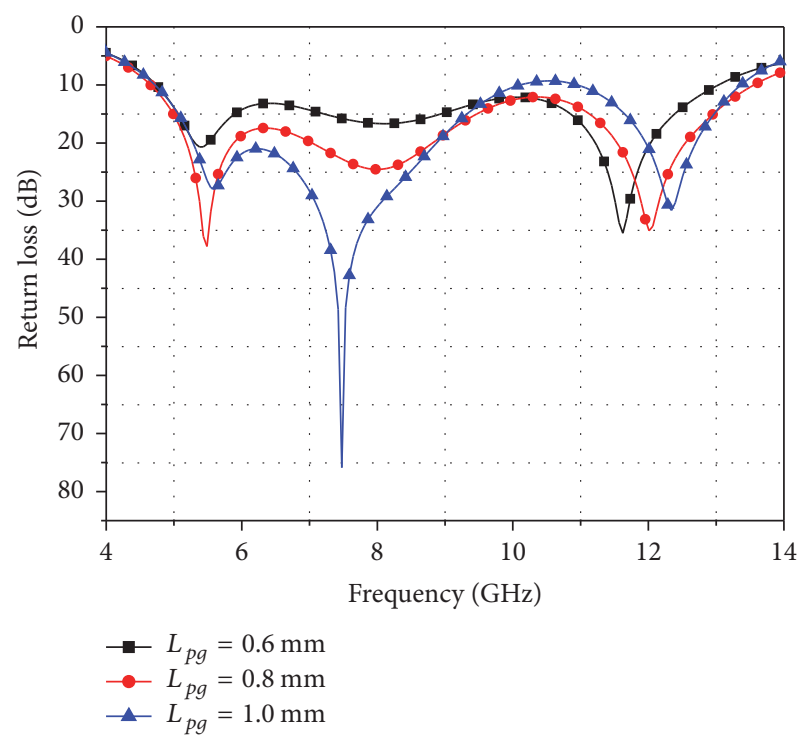

FIGURE 12: Simulated return loss against frequency for the proposed defected substrate wideband antenna with various $L_{p g}$; other parameters are the same as listed in Table 1.

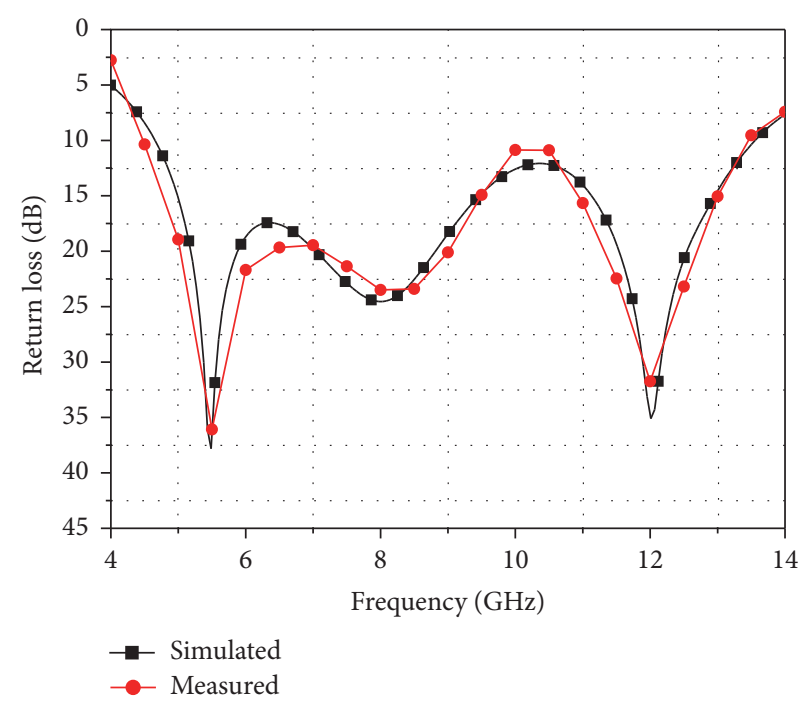

FIGURE 13: Simulated and measured return loss for the proposed defected substrate wideband antenna.

the optimum value with the bandwidth from 4.5 to $13.5 \mathrm{GHz}$, covering the entire wideband.

\section{Experimental Results and Discussion}

The performances of the proposed antenna such as return loss and radiation pattern are measured using Agilent 8757E scalar network vector analyzer. There is a good agreement between simulated and measured results of the proposed defected substrate CPW-fed wideband antenna as shown in Figure 13. The minute variation between measured and simulated result is due to the effect of SMA (subminiature version A) connector soldering and fabrication tolerance. 

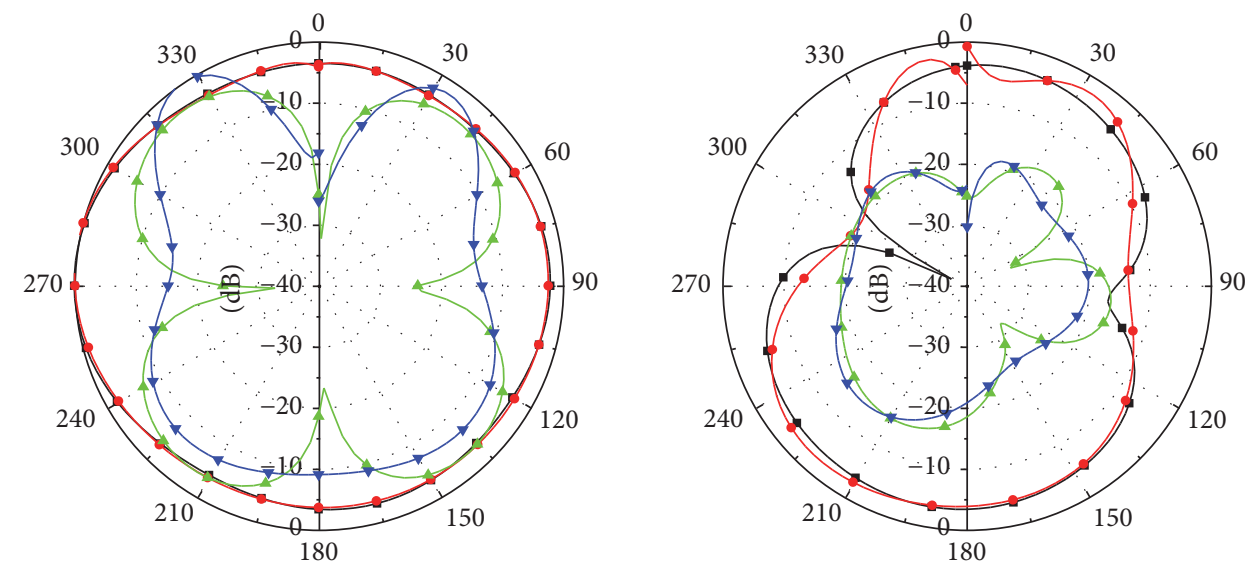

$\rightarrow$ E Co pol simulated $\rightarrow$ E Cross pol simulated
$\rightarrow-E$ Co pol measured
$\rightarrow-E$ Cross pol measured

$\rightarrow H$ Co pol simulated $-H$ Cross pol simulated
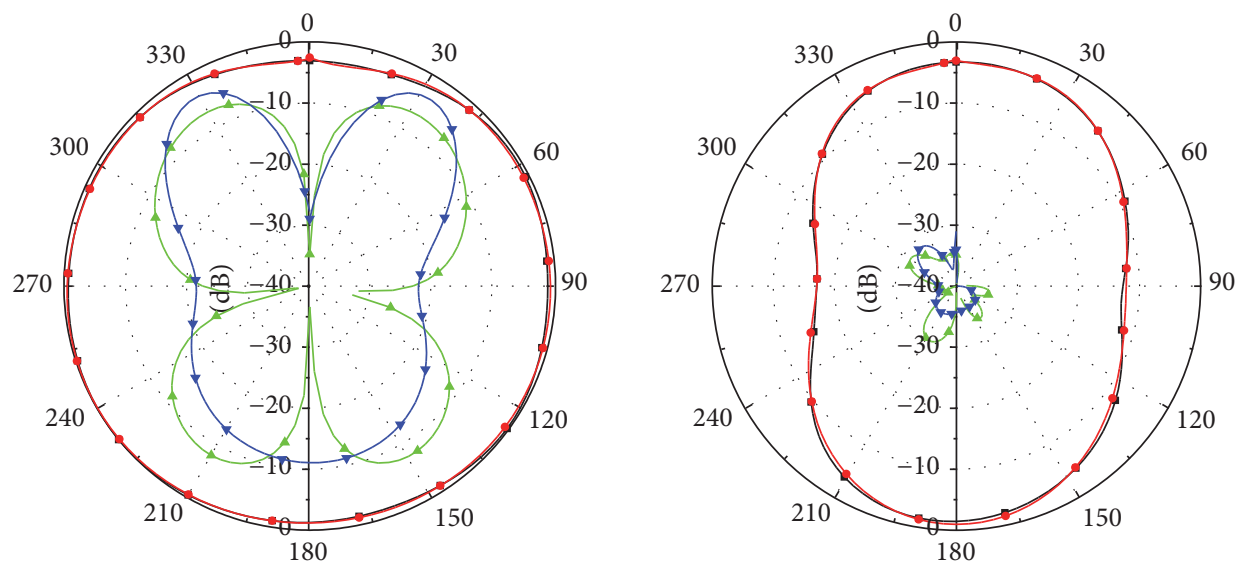

$\rightarrow$ E Co pol simulated $\triangle-E$ Cross pol simulated

$\rightarrow H$ Co pol simulated $-H$ Cross pol simulated E Co pol measured $\neg-E$ Cross pol measured

- $H$ Co pol measured $\rightarrow-H$ Cross pol measured

(b)
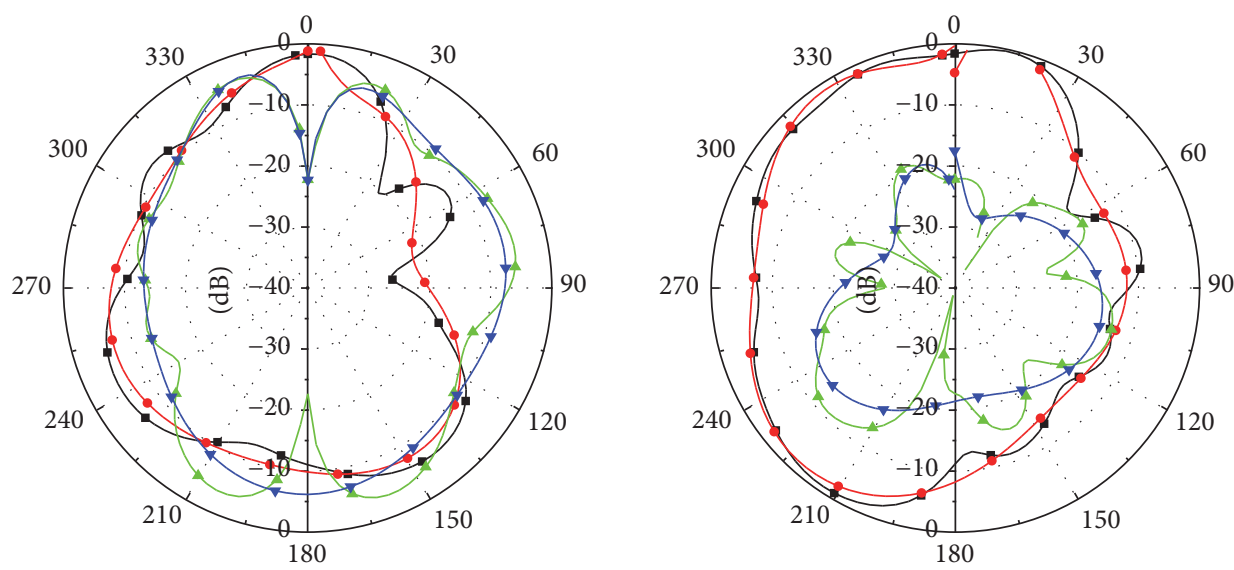

E Co pol simulated $-E$ Cross pol simulated E Cross pol measured

$H$ Co pol simulated $-H$ Cross pol simulated $H$ Co pol measured $\rightarrow-H$ Cross pol measured

(c)

FIGURE 14: Radiation patterns at various frequencies of proposed defected substrate wideband antenna: (a) $5.48 \mathrm{GHz}$, (b) $8.03 \mathrm{GHz}$, and (c) $12.01 \mathrm{GHz}$. 


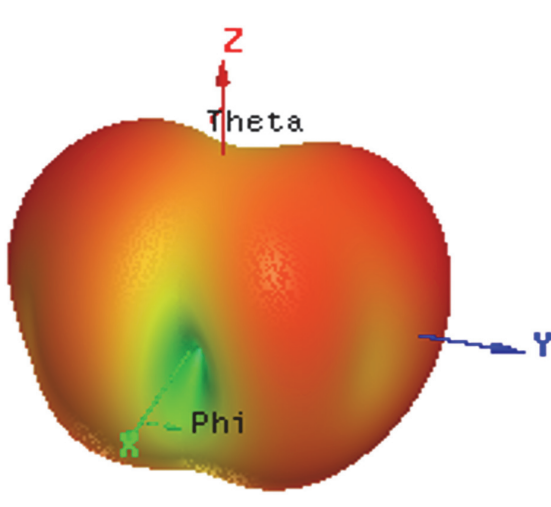

(a)
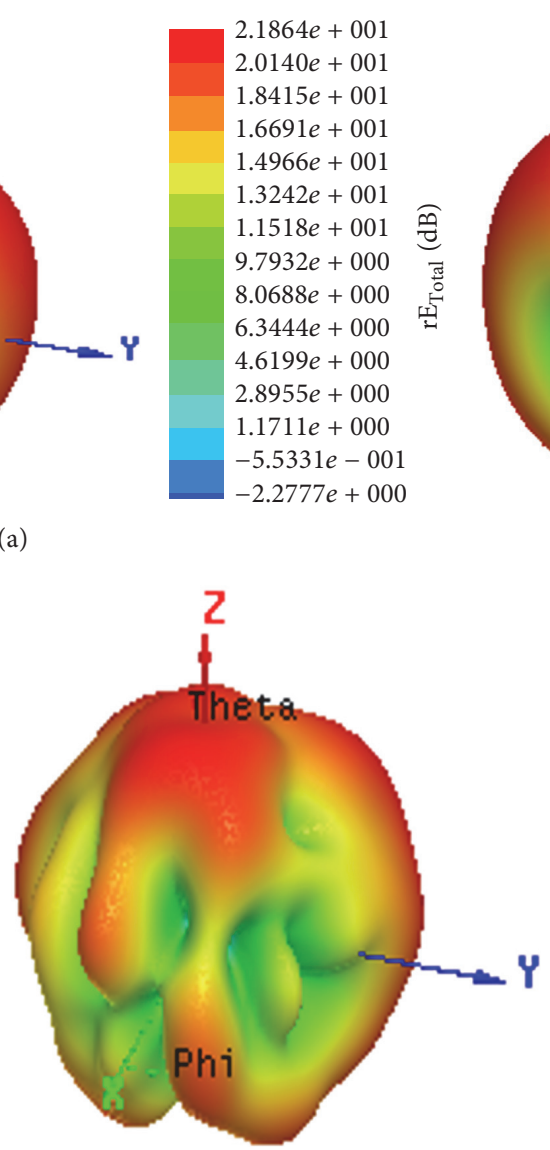

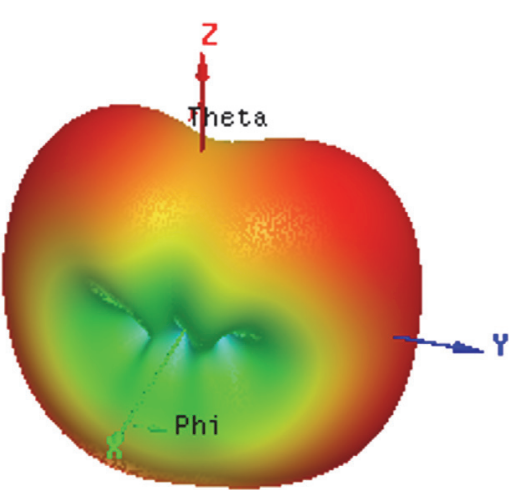

(b)

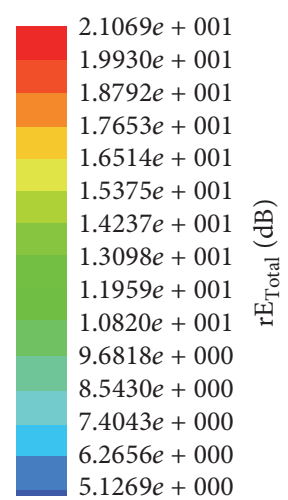

$5.1269 e+000$

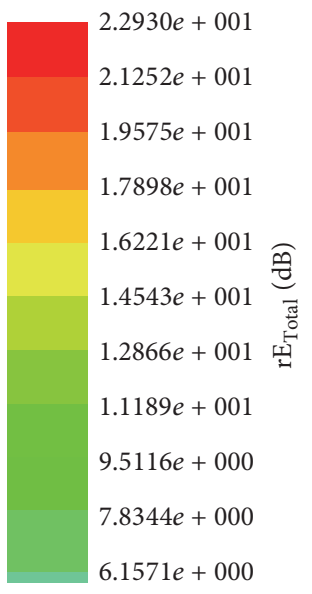

(c)

Figure 15: 3D polar plot at various frequencies of proposed defected substrate wideband antenna: (a) $5.48 \mathrm{GHz}$, (b) $8.03 \mathrm{GHz}$, and (c) $12.01 \mathrm{GHz}$.

The designed antenna offers a bandwidth of $9.0 \mathrm{GHz}$ (4.5 to 13.5 GHz) that meets the bandwidth requirements for $\mathrm{C}$ and $\mathrm{X}$ band applications.

The proposed antenna illustrates good radiation pattern characteristics as shown in Figures 14(a)-14(c). The radiation patterns in $H$ and $E$ planes are at sampling frequencies of $5.48,8.03$, and $12.01 \mathrm{GHz}$, respectively. Patterns are distorted because the ground plane is a part of loop path; the surface current on the radiating plane changes the effective current distribution of the loop and results in distortion. These patterns are suited for application in numerous wireless communication systems, as expected. Measured and simulated results of radiation patterns show good agreement.

Figure 15 shows good results of $3 \mathrm{D}$ polar plot of proposed defected substrate wideband antenna at three resonant frequencies $5.48 \mathrm{GHz}, 8.03 \mathrm{GHz}$, and $12.01 \mathrm{GHz}$. The 3D polar plot gives and additional view for the distribution of the power radiated in space.

Figure 16 illustrates the group delay of the proposed antenna. Group delay is a significant factor in the designing of wideband antenna as it tells about the distortion of the transmitted pulses in the wireless communication. It is observed that the group delay for the proposed antenna is stable and less than $1 \mathrm{~ns}$ for entire operating bandwidth 4.5 to

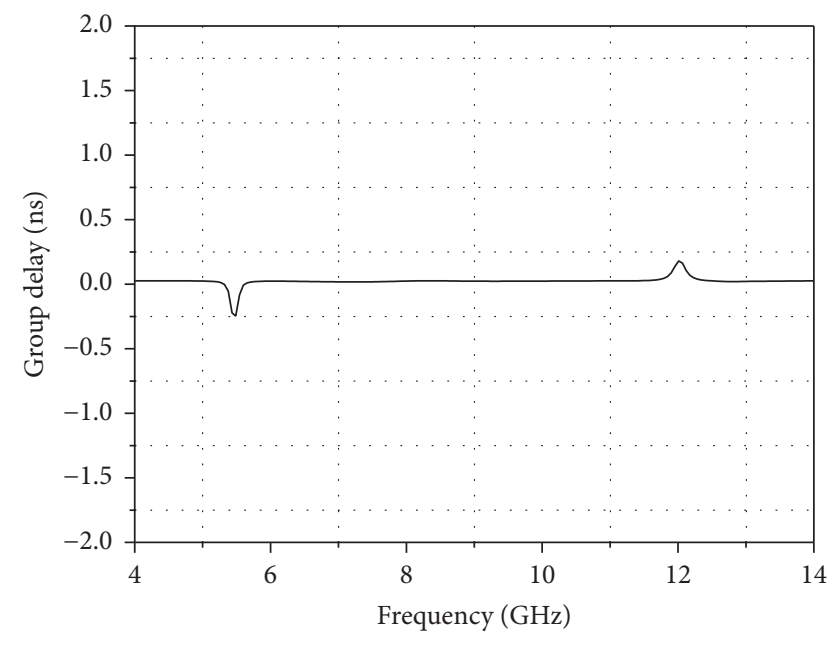

FIGURE 16: Group delay for the proposed defected substrate wideband antenna.

13.5 GHz. For distortion less transmission, group delay should be less than $1 \mathrm{~ns}$ in the wideband antenna.

Gain is an important parameter in the designing of wideband microstrip patch antennas. Figure 17 demonstrates 
TABLE 2: Comparison of reference antennas with proposed antenna.

\begin{tabular}{|c|c|c|c|c|c|c|}
\hline S. number & Reference number & Antenna type & Overall size $\left(\mathrm{mm}^{3}\right)$ & $\begin{array}{c}\text { Operating } \\
\text { frequency band } \\
(\mathrm{GHz})\end{array}$ & $\begin{array}{c}\text { Relative } \\
\text { dielectric } \\
\text { constant }\left(\epsilon_{r}\right)\end{array}$ & Applications \\
\hline 1 & [1] & Wideband & $32 \times 30 \times 1.58$ & $3.32-6.5$ & 4.4 & WLAN/WiMAX \\
\hline 2 & [2] & Wideband & $25 \times 25 \times 1.6$ & $2.96-7.95$ & 4.4 & $\mathrm{~S}$ and $\mathrm{C}$ band \\
\hline 3 & {$[4]$} & Wideband & $38 \times 25 \times 1.6$ & $2.4-6.0$ & 4.4 & WLAN/WiMAX \\
\hline 4 & {$[13]$} & UWB & $25 \times 25 \times 1.6$ & $2.9-11.5$ & 4.4 & UWB \\
\hline 5 & [19] & UWB & $18 \times 25 \times 1.25$ & $2.0-10.6$ & 4.4 & UWB \\
\hline 6 & Proposed antenna & Wideband & $42 \times 36 \times 1.6$ & $4.5-13.5$ & 4.4 & $\mathrm{C}$ and $\mathrm{X}$ band \\
\hline
\end{tabular}

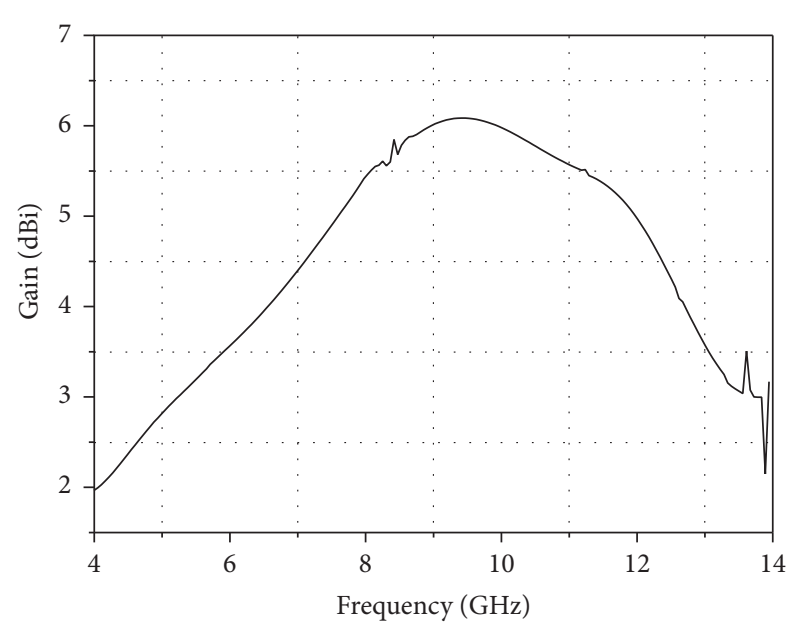

Figure 17: Gain for the proposed defected substrate wideband antenna.

the gain of the proposed antenna. It was found out that the gain of the antenna varies within 1.9 to $6.08 \mathrm{dBi}$ against the frequency band of 4.5 to $13.5 \mathrm{GHz}$.

Antenna radiation efficiency is defined as the ratio of power radiated to the input power. It is related to the gain and directivity of the patch antenna. Radiation efficiency also considers the conduction and dielectric losses. The radiation efficiency of the proposed antenna is shown in Figure 18. It exhibits $79.35 \%, 75.66 \%$, and $86.44 \%$ radiation efficiency at three resonant frequencies $5.48 \mathrm{GHz}, 8.03 \mathrm{GHz}$, and $12.01 \mathrm{GHz}$.

Table 2, illustrates the comparison between the proposed (defected substrate) antenna and some other existing antennas in terms of the antenna type, overall size, operating frequency band, dielectric constant and applications. The comparative chart shows that the proposed antenna has defected substrate and wideband applications with respect to other antenna of different dimension and shapes.

\section{Conclusion}

A novel CPW-fed defected substrate patch antenna is fabricated and proposed for wideband applications. The proposed antenna achieves good return loss, constant group delay, and good radiation patterns over the entire operating bandwidth

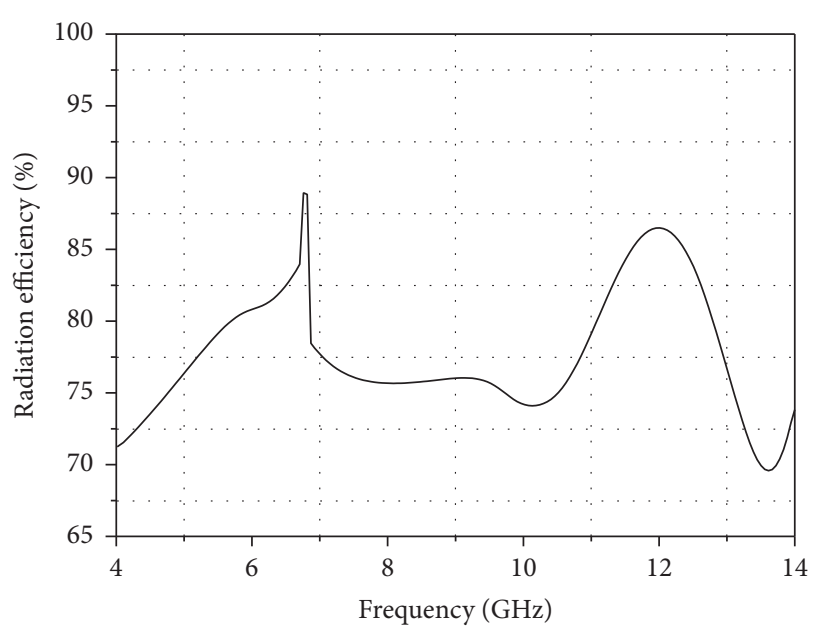

FIGURE 18: Radiation efficiency for the proposed defected substrate wideband antenna.

from 4.5 to $13.5 \mathrm{GHz}(9.0 \mathrm{GHz})$ with $100 \%$ impedance bandwidth. The gain of the proposed antenna reaches a peak value of $6.08 \mathrm{dBi}$, while the radiation efficiency of proposed antenna reaches a maximum value of $88 \%$. The simulated and measured results of the projected antenna show balanced agreement. The proposed antenna can be used in numerous wireless applications.

\section{Competing Interests}

The authors declare that there are no competing interests regarding publication of this paper.

\section{References}

[1] A. Singh and S. Singh, "A novel CPW-fed wideband printed monopole antenna with DGS," AEU-International Journal of Electronics and Communications, vol. 69, no. 1, pp. 299-306, 2014.

[2] P. Khanna, A. Sharma, K. Shinghal, and A. Kumar, "A defected structure shaped CPW-fed wideband microstrip antenna for wireless applications," Journal of Engineering, vol. 2016, Article ID 2863508, 7 pages, 2016.

[3] A. Nouri and G. R. Dadashzadeh, "A compact UWB bandnotched printed monopole antenna with defected ground 
structure," IEEE Antennas and Wireless Propagation Letters, vol. 10, pp. 1178-1181, 2011.

[4] A. K. Gautam, A. Bisht, and B. K. Kanaujia, "A wideband antenna with defected ground plane for WLAN/WiMAX applications," AEU-International Journal of Electronics and Communications, vol. 70, pp. 354-358, 2016.

[5] J. Pei, A.-G. Wang, S. Gao, and W. Leng, "Miniaturized tripleband antenna with a defected ground plane for WLAN/ WiMAX applications," IEEE Antennas and Wireless Propagation Letters, vol. 10, pp. 298-301, 2011.

[6] M. A. Antoniades and G. V. Eleftheriades, "A compact multiband monopole antenna with a defected ground plane," IEEE Antennas and Wireless Propagation Letters, vol. 7, pp. 652-655, 2008.

[7] K. H. Chiang and K. W. Tam, "Microstrip monopole antenna with enhanced bandwidth using defected ground structure," IEEE Antennas and Wireless Propagation Letters, vol. 7, pp. 532$535,2008$.

[8] M. K. Khandelwal, B. K. Kanaujia, S. Dwari, S. Kumar, and A. K. Gautam, "Analysis and design of wide band Microstripline-fed antenna with defected ground structure for $\mathrm{Ku}$ band applications," AEU-International Journal of Electronics and Communications, vol. 68, no. 10, pp. 951-957, 2014.

[9] S. S. Kumar, G. S. Rao, and R. Pillalamarri, "Rectangular slotted microstrip line fed compact printed antenna with etched ground plane for UWB communications," Microsystem Technologies, vol. 21, no. 10, pp. 2077-2081, 2014.

[10] M. Bitchikh, R. Aksas, A. Azrar, and H. Kimouche, "A 2.3-14 $\mathrm{GHz}$ UWB planar octagonal antenna with modified ground plane," Microwave and Optical Technology Letters, vol. 55, no. 3, pp. 479-482, 2013.

[11] A. A. Adam, S. K. A. Rahim, K. G. Tan, and A. W. Reza, "Design of 3.1-12 GHz printed elliptical disc monopole antenna with half circular modified ground plane for UWB application," Wireless Personal Communications, vol. 69, no. 2, pp. 535-549, 2013.

[12] A. C. Shagar and R. S. D. Wahidabanu, "New design of CPWfed rectangular slot antenna forultra wideband applications," International Journal of Electronics Engineering, vol. 2, pp. 6973, 2010.

[13] M. K. Shrivastava, A. K. Gautam, and B. K. Kanaujia, "A novel a-shaped monopole-like slot antenna for ultrawideband applications," Microwave and Optical Technology Letters, vol. 56, no. 8, pp. 1826-1829, 2014.

[14] B. R. S. Reddy and D. Vakula, "Compact zigzag-shaped-slit microstrip antenna with circular defected ground structure for wireless applications," IEEE Antennas and Wireless Propagation Letters, vol. 14, pp. 678-681, 2015.

[15] Km. Kamakshi, A. Singh, M. Aneesh, and J. A. Ansari, "Novel design of microstrip antenna with improved bandwidth," International Journal of Microwave Science and Technology, vol. 2014, Article ID 659592, 7 pages, 2014.

[16] S. M. Naveen, R. M. Vani, and P. V. Hunagund, "Compact wideband rectangular monopole antenna for wireless applications," Wireless Engineering and Technology, vol. 3, no. 4, pp. 240-243, 2012.

[17] N. Prombutr, P. Kirawanich, and P. Akkaraekthalin, "Bandwidth enhancement of UWB microstrip antenna with a modified ground plane," International Journal of Microwave Science and Technology, vol. 2009, Article ID 821515, 7 pages, 2009.
[18] R. Kumar, P. Naidu V, and V. Kamble, "A compact asymmetric slot dual band antenna fed by CPW for PCS and UWB applications," International Journal of RF and Microwave ComputerAided Engineering, vol. 25, no. 3, pp. 243-254, 2015.

[19] K. Q. Da Costa and V. Dmitriev, "Planar monopole UWB antenna with cuts at the edges and two parasitic loops," Journal of Microwaves and Optoelectronics, vol. 8, no. 1, pp. 92-100, 2009.

[20] Ansoft Corporation, Ansoft High-Frequency Structure Simulator (HFSS), Version 14.0, Ansoft Corporation, Pittsburgh, Pa, USA.

[21] C. A. Balanis, Antenna Theory: Analysis and Design, WileyInterscience, 3rd edition, 2012.

[22] M. Habib Ullah, M. T. Islam, J. S. Mandeep, N. Misran, and N. Nikabdullah, "A compact wideband antenna on dielectric material substrate for K band," Electronics and Electrical Engineering, vol. 123, no. 7, pp. 75-78, 2012.

[23] Y. S. Wu and F. J. Rosenbaum, "Mode chart for microstrip ring resonators (Short Papers)," IEEE Transactions on Microwave Theory and Techniques, vol. 21, no. 7, pp. 487-489, 1973.

[24] P. Mythili and A. Das, "Theoretical investigations of an annular elliptical ring microstrip antenna using Green's function technique," IEEE Proceedings Microwave, Antenna Propagation, vol. 146, no. 6, pp. 379-384, 1999. 


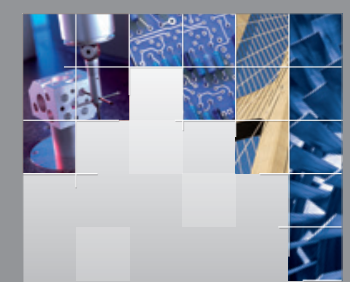

\section{Enfincering}
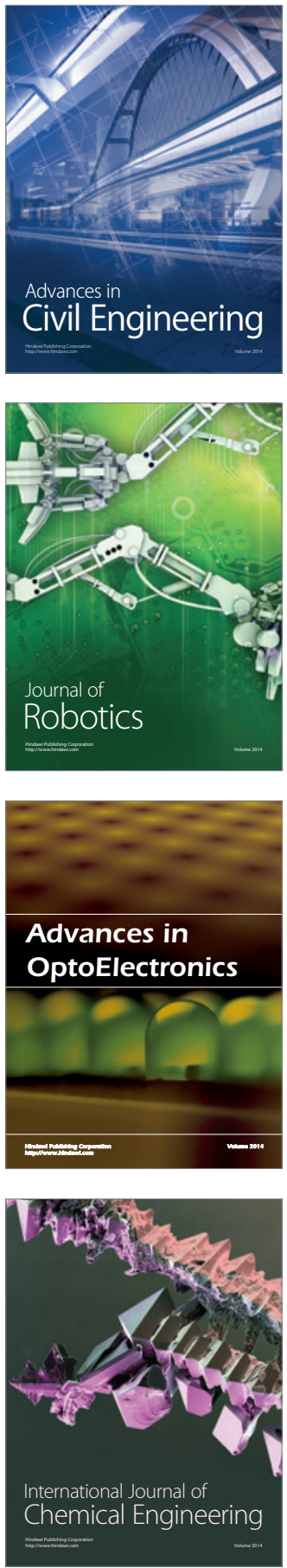

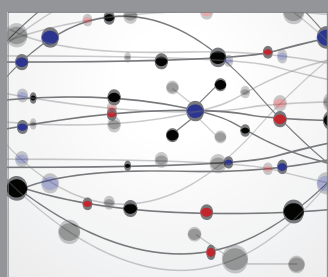

The Scientific World Journal

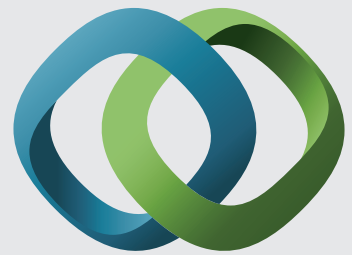

\section{Hindawi}

Submit your manuscripts at

http://www.hindawi.com
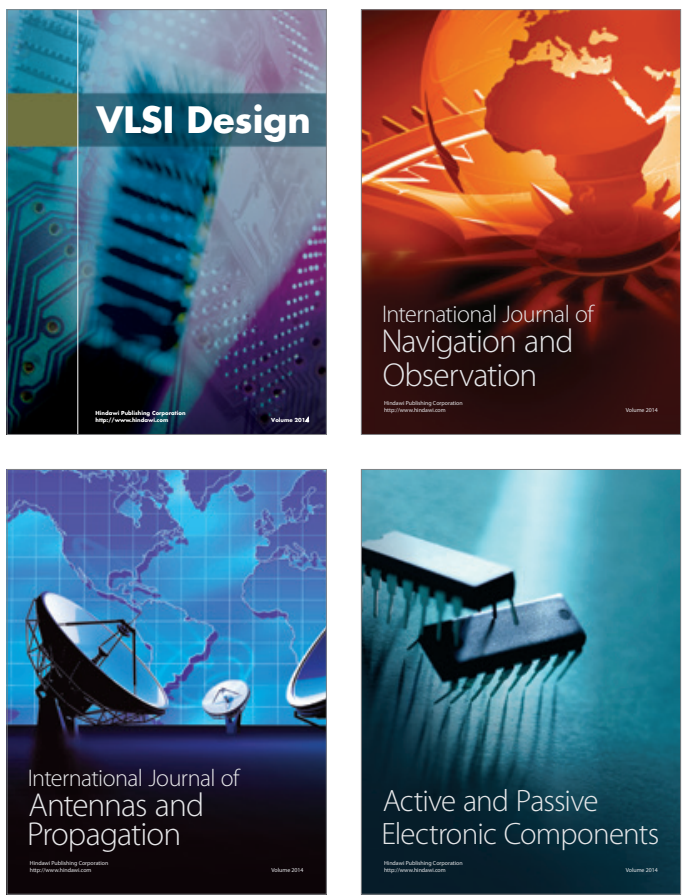
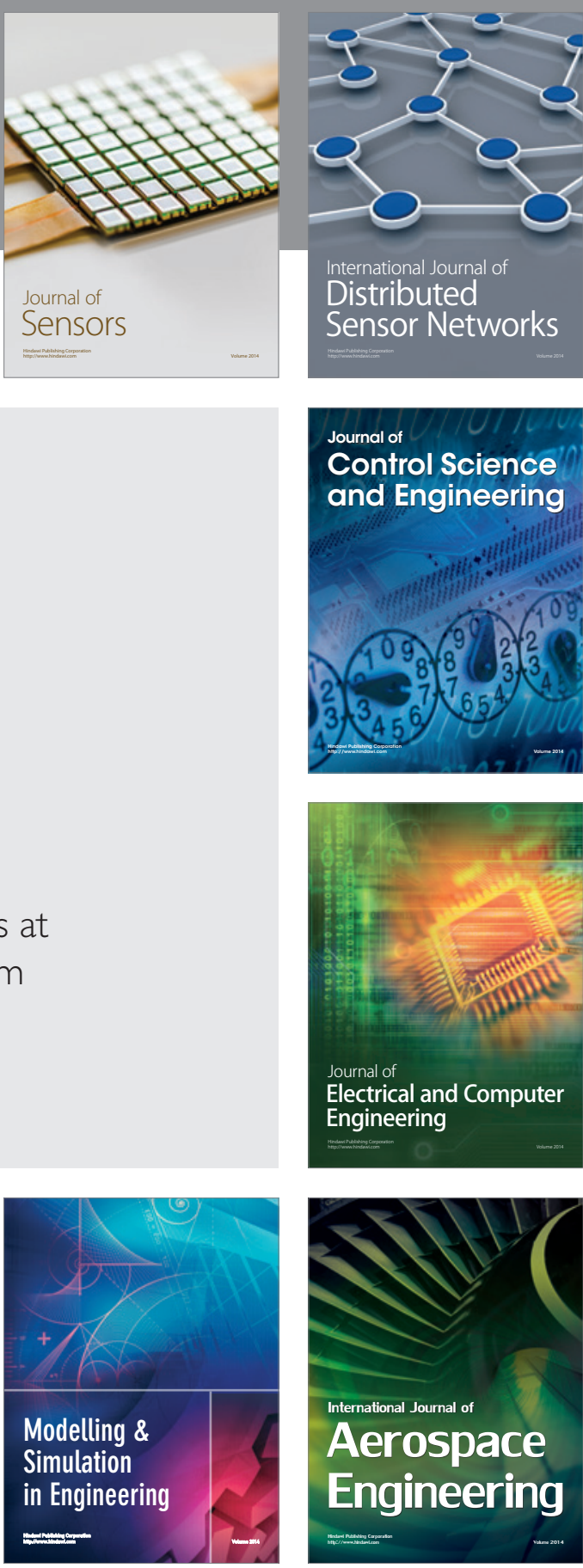

International Journal of

Distributed

Sensor Networks

Journal of

Control Science

and Engineering
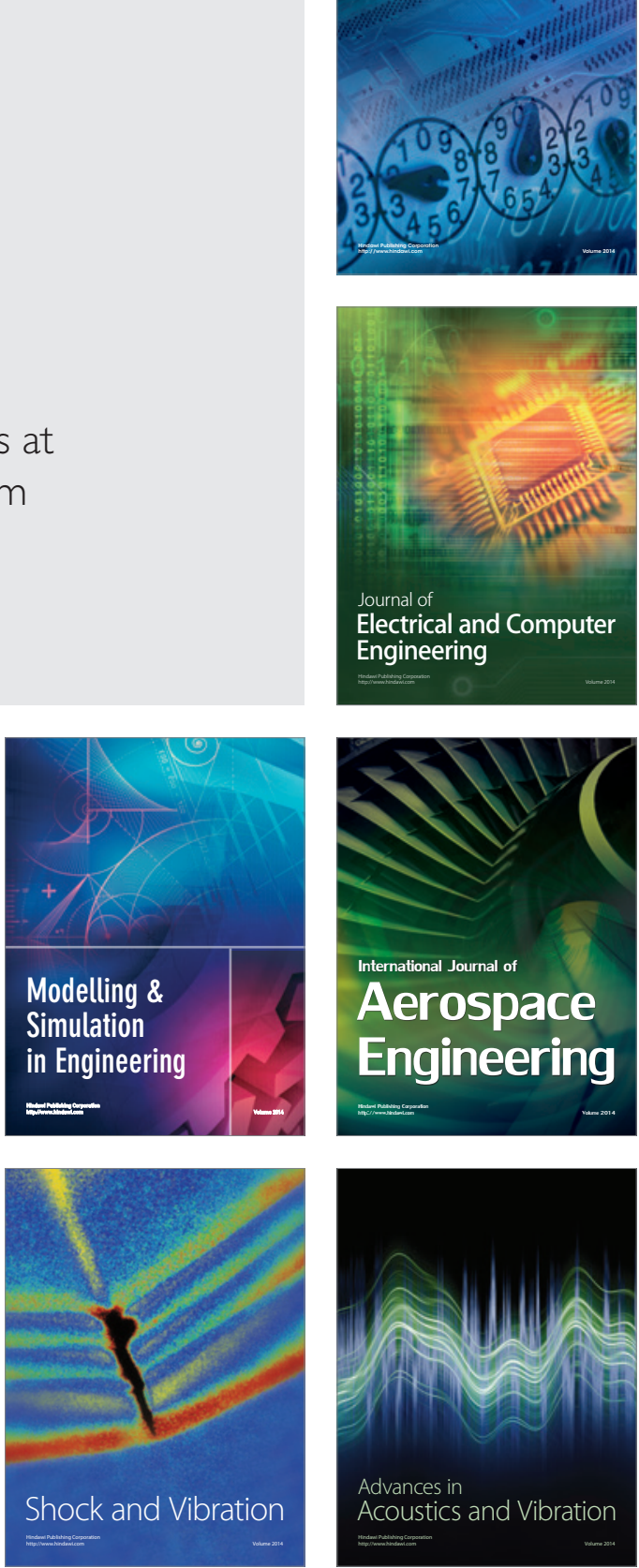